\title{
Design and Analysis of an Off-Grid PV Plant for Higher Utilization Efficiency in The Field of Pharmaceutical Industry Considering Global Pandemic State
}

\author{
A.B.M. Khalid Hassan and Kazi Firoz Ahmed
}

\begin{abstract}
According to the concern of WHO the less association of people in an office may restrict the likelihood of spreading this COVID-19 infection. On the other hand, the pharmaceutical companies are working hard to maintain uninterrupted production of vaccine and medicines. This paper focuses on the main layer which is the power system management and its utilization through automation and controlling remotely. In the design process the FDA (Food and Drug Administration) proposed structure and green energy solution is maintained. Solar energy utilization efficiency is increased using the data logging system and machine learning algorithms from archived data. A SCADA operated Off-Grid Solar PV Automation System has been proposed to increase the utilization efficiency. To predict solar power availability over time and perform efficient energy trafficking, the automation system will analyze previous data and perform situational awareness operations for uninterrupted solar power generation. A comprehensive analysis of the proposed automation system for pharmaceuticals industry applications has also been presented in this paper. The continuous monitoring system for this Off-Grid Solar PV power generating unit preserves multiple data entries, which increases with time and subjected to energy trafficking. And this energy trafficking based on machine learning increases the overall solar energy utilization efficiency from $64 \%$ to $99.92 \%$.
\end{abstract}

Index Terms-SCADA, Automation, Solar PV, Energy Trafficking

\section{INTRODUCTION}

$\mathrm{I}^{\mathrm{N}}$ $\mathrm{N}$ pharmaceutical product manufacturing, an automation system in industry is evolving significantly over recent years [1]. The benefits are lower production cycle times, improved manufacturing efficiency, reduced rejects and increased production operating time [2].

A.B.M. Khalid Hassan is a Graduate Student, EEE Department, American International University-Bangladesh (AIUB) 408/1, Kuratoli, Khilkhet, Dhaka-1229, Bangladesh. Email: a.b.m.khalid.hassan@gmail.com

Kazi Firoz Ahmed is a Senior Assistant Professor of the Department of EEE, American International University Bangladesh,408/1, Kuratoli, Khilkhet, Dhaka-1229, Bangladesh. Email: k.firoz@aiub.edu
Beside production machineries process automation [3-4], water storage and distribution system, warehouse monitoring and control system, clean room automation, Building Management System (BMS), HVAC control system [5-9], etc. are also utilizing the benefits of automation for energy audit and energy saving options [10]. Roof top solar photovoltaic energy generation system is also being used in pharmaceutical industry applications over time [11-12] without any automation system combining PLC and SCADA for monitoring and control, data logging, energy trafficking or optimizing the overall energy utilization efficiency. Current studies and practices of installing a solar PV system is focused on energy generation efficiency by maximum power extraction with different MPPT algorithms, Sun Tracking and efficient energy conversion methods [13-17]. In this paper, an off-grid solar PV energy generation system has been designed for pharmaceutical industry application considering PLC and SCADA automation focusing on generated energy utilization efficiency. PLC and SCADA automation system is being widely used in solar power plants for monitoring and control, data logging, energy auditing, energy forecasting, distribution control and situational awareness [18-24]. That methodology has been considered to develop this proposed system which is specifically designed for pharmaceutical industry applications.

As all the pharmaceuticals manufacturing facilities are bound to maintain some guidelines of different regulatory authorities (Like, FDA 21 CFR Part 11, CE cGMP Annex 11, ISPE GAMP $\mathrm{V}$, etc.) [25-27], they must have to ensure continuous power to their facility by installing online UPS system where inbuilt DC power storage is required. Most of the DC power storages are designed to provide backup for a minimum of 15 minutes to the respective load during a power failure. The off-grid solar PV system also requires inbuilt DC power storage for continuous power supply. The energy trafficking automation system allows us to use the DC power storage of online UPS systems directly with an off-grid solar PV system. The primary advantage of a supervisory control and data acquisition (SCADA) system is monitoring and control of any unit. Moreover, an automation system is capable of making adequate discissions based on available information. The reliability of an automated system is higher than manual systems. The user access level can be 
controlled in a SCADA system, based on the user authority level of taking discissions. The audit trail of user activity, alarm and event logging, as well as trend data logging, are some basic features of any SCADA system. High-level data integration is an essential part of an automation system, where different components of the entire system containing different communication protocols (Like, BACnet, Modbus, LonTalk, PROFINET, etc.) can exchange data. Programmable logic controller (PLC) network is capable of directly controlling specific systems and read low-level data from any analogue or digital sensor throw its peripheral input and output interface. PLC network directly monitors and control the system in lowlevel and communicate with the SCADA system in high-level. In any pharmaceutical manufacturing facility, all the different units contain automation system. Process automation, building automation, industrial automation, etc. are being widely used in all pharmaceutical manufacturing facilities. Power system automation is widespread for large scale power generation plants and smart power grid applications. Low scale renewable energy generation units like off-grid rooftop solar PV systems are usually designed for outdoor lightings and unclassified area overhead lighting in most of the pharmaceuticals industry applications, due to unavailability of continuous solar irradiance and battery-based solution, the off-grid rooftop solar PV system usually not been used for classified areas of pharmaceutical manufacturing facilities. The reliability of the off-grid rooftop solar PV system can be optimized for classified areas of pharmaceutical manufacturing facilities with the power system automation.

The rest of the paper is organized as follows. In Section II, design overview of the proposed automation system, section III explains the operational process and analysis of the proposed automation system, section IV does the analysis of the overall system, section $\mathrm{V}$ is about feasibility study of the proposed system for pharmaceutical industry applications, section VI is about the result analysis and section VII is the conclusion.

\section{Automation System DESign}

The proposed automation system contains a Programmable logic controller (PLC) network to monitor and control the solar plant field equipment and communicates with the SCADA server. Fig. 1 represents the system architecture of the entire automation system. The Energy Trafficking operation will be performed with the help of Supply Prediction and Load Forecasting.

The Supply Prediction will be performed by utilizing the available field data which will be collected and archived from the environment, solar PV panel and the DC power generation control unit. The possible data of these area are been discussed below.

\section{A. Environmental Data}

The Environmental Data Monitoring Unit will contain both satellite data for plant location and field sensor data from the plant. It continuously monitors Global Horizontal Irradiance (GHI, W/m2), the total irradiance received on a horizontal surface; Direct (Beam) Horizontal Irradiance (EBH, W/m2), the

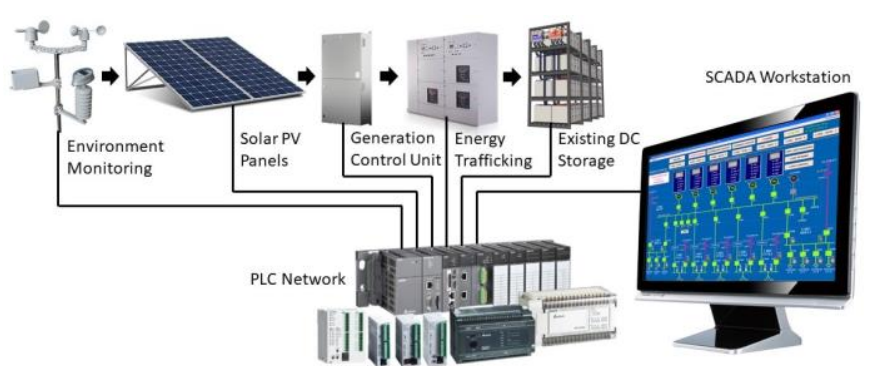

Fig. 1. System Architecture of the proposed Off-Grid Solar PV Automation System for Pharmaceutical Industry Applications.

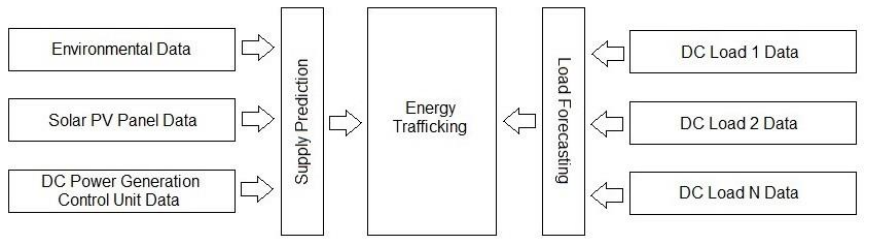

Fig. 2. Block Diagram of the Proposed Automation System of an Off-Grid Solar PV energy generation unit for Pharmaceutical Industry Applications.

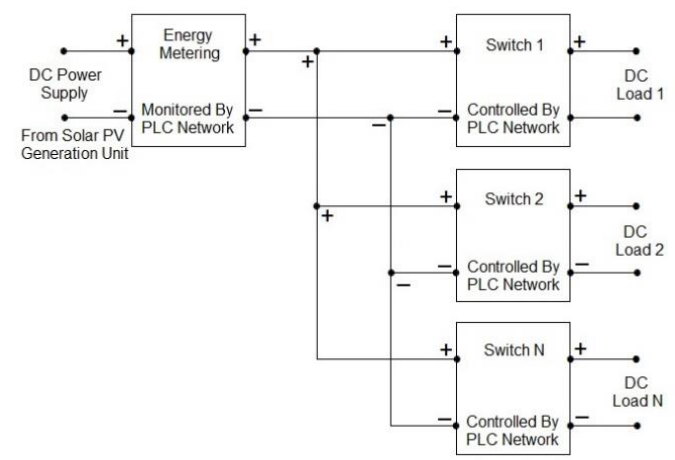

Fig. 3. Solar Energy Trafficking Unit Design of the proposed automation system.

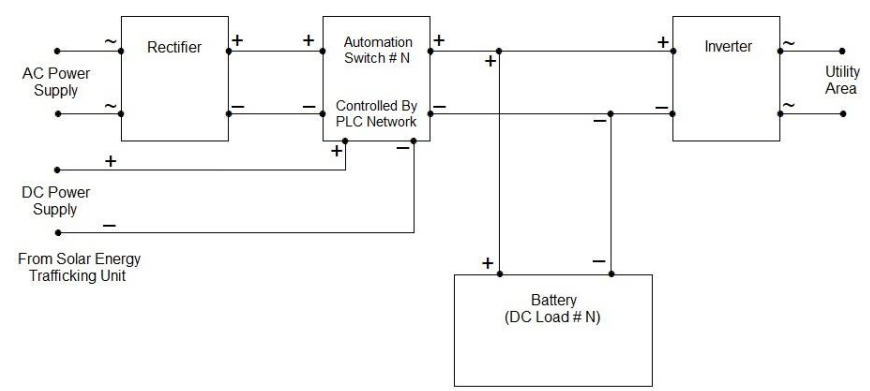

Fig. 4. Solar PV system generated DC power supply to the existing DC power storage unit of pharmaceutical manufacturing facility online UPS system.

horizontal component of Direct Normal Irradiance; Direct Normal Irradiance (DNI, W/m2), solar irradiance arriving in a direct line from the sun as measured on a surface held perpendicular to the sun; Diffuse Horizontal Irradiance (DIF, DHI, W/m2), the horizontal component of diffuse irradiance (irradiance that is scattered by the atmosphere); Temperature (TEMP, Celsius), the temperature of the air in the given location (10 meters above ground level); Solar Zenith (degrees), the angle between a line perpendicular to the earth's surface and the sun (90 deg = sunrise and sunset; $0 \mathrm{deg}=$ sun directly overhead), Solar Azimuth (degrees), the angle between a line pointing due north to the sun's current position in the sky, 
negative to the east, positive to the west, 0 at due north; Cloud Opacity (\%), the measurement of how opaque the clouds are to solar radiation in the given location; Dewpoint (DWPT, Celsius), the air dewpoint temperature (2 meters above ground level); Relative Humidity (RH, \%), the air relative humidity (2 meters above ground level); Surface Pressure (AP, hPa), the air pressure at ground level; Wind Speed (WS, $\mathrm{m} / \mathrm{s}$ ), the wind speed (10 meters above ground level); Wind Direction (WD, degrees), the wind direction (10 meters above ground level) where 0 is a northerly (from the north), 90 is an easterly (from the east), 180 is a southerly (from the south), 270 is a westerly (from the west); Precipitable Water (PWAT, $\mathrm{kg} / \mathrm{m} 2$ ), the total column precipitable water content; Snow depth (SWDE, cm), the snow depth liquid-water-equivalent [28]; etc.

\section{B. Solar PV Panel Data}

In the solar PV panel unit, the monitored parameters include panel temperature monitoring, cleanliness monitoring, physical damage monitoring (like yellowing and browning, delamination, bubbles in the solar module, cracks in cells, defects in the anti-reflective coating, hot spots caused by the panel acting as a load [29], edge-seal delamination, newly cracked cells, delamination over cells and interconnections, split encapsulation over cells and interconnections, protruding interconnections [30], connections and the welds degradation [31], etc.), irradiance interruption monitoring, ambient light illuminance monitoring, etc.

\section{DC Power Generation Control Unit Data}

From the DC power generation unit, the monitoring data will be the generated DC voltage, current, power, etc. for individual modules, cable fault, array connection fault, combiner unit monitoring, MPPT unit monitoring, surge protector monitoring, earthing and lightning arrestor monitoring, switching devices monitoring, array junction box monitoring, power quality monitoring, disturbance fault analyzer monitoring, string combiner monitoring data, etc. This monitoring and control system is independent of any particular MPPT algorithms or other analyzing mechanisms. Each MPPT algorithms and other analyzing mechanisms will be monitored and controlled by this system with data logging and situational awareness options.

The energy trafficking unit will be directly controlled and monitored by the PLC network at low level peripheral I/O points. The automation system will decide the trafficking requirement based on supply prediction and load forecasting. The block diagram which gas been represented in Fig. 2 shows that both the load side and the generation side are connected with the energy trafficking process. The continuous monitoring of environmental data, solar PV panel data, DC power generation control unit data, etc. will be utilized for supply prediction. The existing DC power storage units of the running online UPS systems of the pharmaceutical manufacturing facility with be the DC Load of the automation system.

Load forecasting will be performed by utilizing all the load data which will be collected and archived from the existing DC power storages of online UPSs installed for the manufacturing facilities. In a large pharmaceutical product manufacturing facility, there are lots of different size of electrical loads which are been equipped with online UPSs. Among those, there are

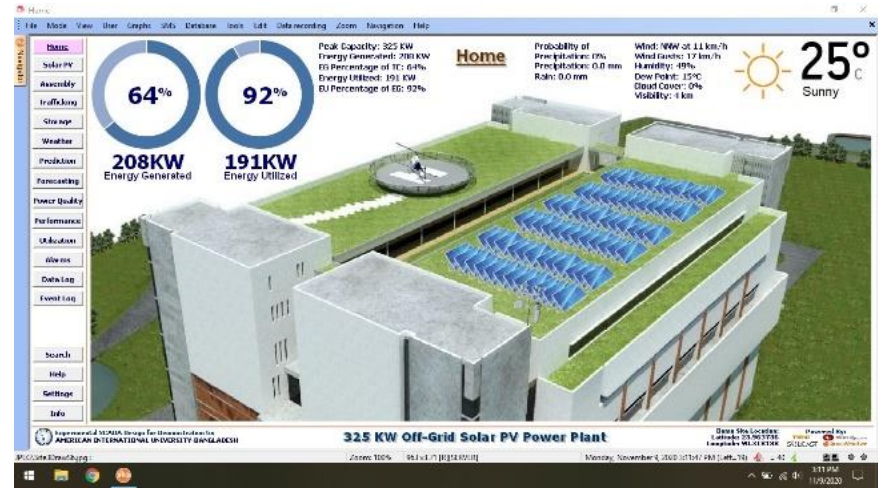

Fig. 5. Supervisory Control and Data Acquisition (SCADA) Graphical User Interface (GUI) implementation.

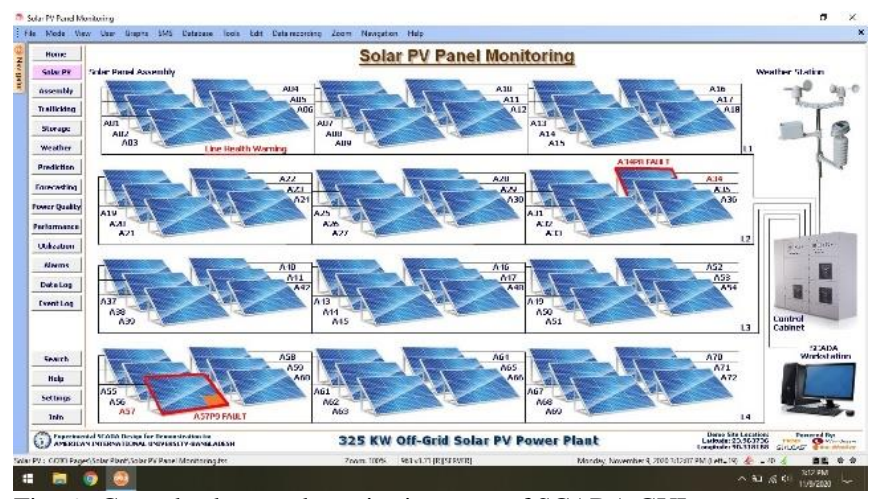

Fig. 6. Central solar panel monitoring page of SCADA GUI.

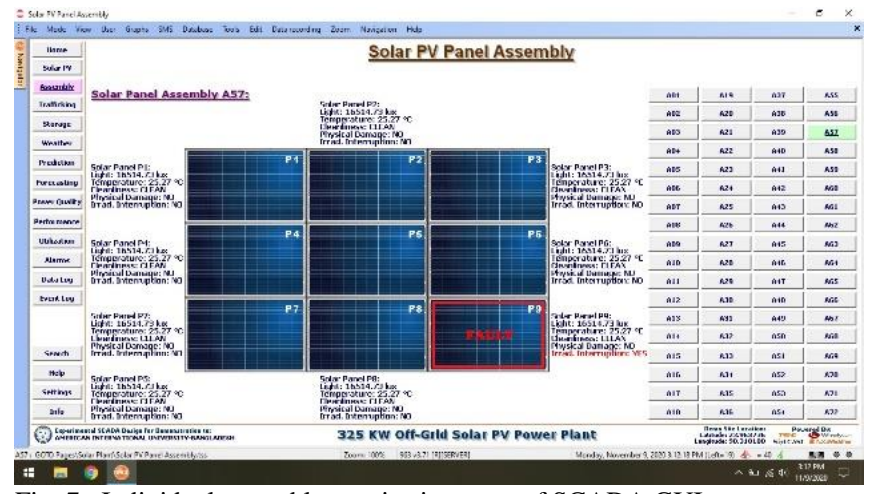

Fig. 7. Individual assembly monitoring page of SCADA GUI.

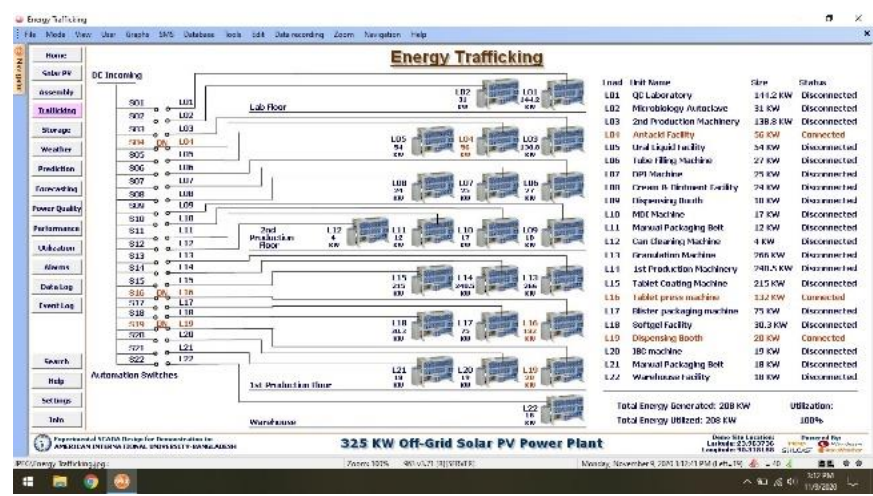

Fig. 8. Energy trafficking page of SCADA GUI.

some heavy loads like HVAC components as well as there are some small loads like plug loads of laboratory equipment. To connect with the proposed system, a single load must have to be smaller than the pick energy generation capacity of the solar 


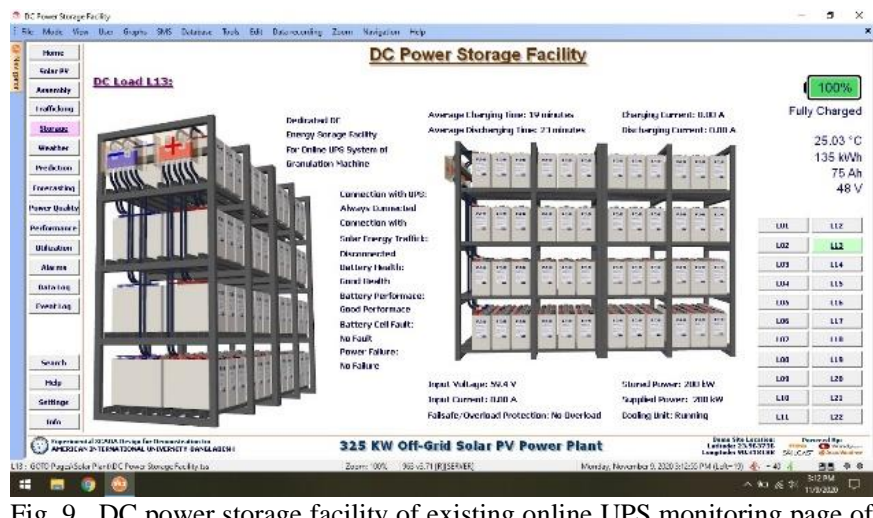

Fig. 9. DC power storage facility of existing online UPS monitoring page of SCADA GUI.

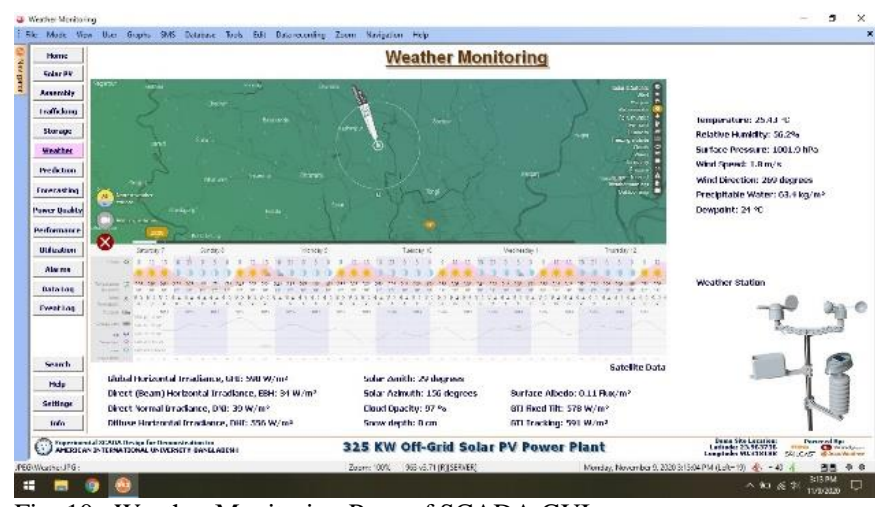

Fig. 10. Weather Monitoring Page of SCADA GUI.

PV unit. After connecting all the online UPS's battery banks of all possible loads with the proposed system through automation switches which will be controlled by the PLC network, the available parameters of the connected battery banks will be monitored and archived for load forecasting. The possible monitoring data of those DC power storage facilities like battery capacity, voltage level, current capacity, charging and discharging current and required time, input voltage and current, stored and supplies power, temperature, cooling unit data, failsafe/overload protection data, static bypass data, etc. will be utilized for load forecasting.

Solar energy trafficking unit design has been presented in Fig. 3. Here, all the connected DC energy storage unit will contain separate automation switch unit which will be controlled by the PLC network. The PLC network will connect the required loads with the DC power supply from solar PV energy generation unit based on the trafficking instruction of the automation system. Fig. 4 shows the process of supplying generated DC power to the storage unit. Inside the online UPS system, after converting the AC power from grid substation of generator, and before inverting into AC power again to supply to the load, the DC power storage unit are been connected. The automation switches will be connected in between the rectifier and the battery unit in this proposed system. As the battery unit will have direct connection with inverter, the load will get an uninterruptable power supply as before. The automation unit will measure the solar PV energy generation as well as the load requirements. Based on that information, the automation unit will decide either to connect or to disconnect the solar PV generated DC power with the battery and inverter unit. The detailed decision-making process has been discussed in the process operation section. The automation switch will connect either rectifier power or Solar generated DC power to the battery and rectifier unit to ensure primary objective of utilizing $100 \%$ of Solar generated DC power.

The PLC network communicates with SCADA server, which is been used as the operator workstation for monitoring and control of the proposed solar system as well as database server. The graphical user interface of the SCADA system allows to monitor the running solar system, control different components, view historical data logs, alarm logs, event logs, user activity $\log \mathrm{s}$, audit trial $\log \mathrm{s}$, etc.

Fig. 5 to Fig. 9 represent some sample SCADA graphical user interface (GUI) pages of the proposed automation system. The PLC network communicates with SCADA server, which is been used as the operator workstation for monitoring and control of the proposed solar system as well as database server. The graphical user interface of the SCADA system allows to monitor the running solar system, control different components, view historical data $\operatorname{logs}$, alarm $\log$, event $\operatorname{logs}$, user activity $\operatorname{logs}$, audit trial logs, etc. The Fig. 5 represents the home page of a roof-top $325 \mathrm{~kW}$ solar PV power plant which has been designed to monitor current amount of energy generation, energy utilization, and some basic weather monitoring data. Fig. 6 is the central solar panel monitoring page from where all the solar PV panel assembly will be monitored. When a panel fault or line fault will occur, the illustration representing that particular faulty component will show the alarm state visually on graphical user interface. To view the detailed parameters of any specific component, operator will click on that component illustration which will redirect to the component specific which loads are been currently connected and which loads are been currently disconnected can be monitored as well as override controlled if necessary. Fig. 9 and Fig. 10 are the DC power storage facility of existing online UPS monitoring page and weather monitoring data from both satellite and locally installed weather station respectively.

\section{AUTOMATION PROCESS OPERATION AND ANALYSIS}

After getting the supply prediction and load forecast, the automation unit will perform energy trafficking. This process operation can be considered as subset sum problem or bounded knapsack problem application. Considering the connectable load set which will be switched by the automation unit as L. The load set $\mathrm{L}$ has been shown in (1).

$L=\left[L_{1}, L_{2}, L_{3}, \ldots \ldots \ldots, L_{n}\right]$

Here, $\mathrm{n}=$ length $(\mathrm{L})=22$ and $\mathrm{L} 1=144.2 \mathrm{~kW}, \mathrm{~L} 2=31 \mathrm{~kW}$, L3 $=138.8 \mathrm{~kW}, \mathrm{~L} 4=56 \mathrm{~kW}, \mathrm{~L} 5=54 \mathrm{~kW}, \mathrm{~L} 6=27 \mathrm{~kW}, \mathrm{~L} 7=$ $25 \mathrm{~kW}, \mathrm{~L} 8=24 \mathrm{~kW}, \mathrm{~L} 9=18 \mathrm{~kW}, \mathrm{~L} 10=17 \mathrm{~kW}, \mathrm{~L} 11=12 \mathrm{~kW}$, L12 $=4 \mathrm{~kW}, \mathrm{~L} 13=266 \mathrm{~kW}, \mathrm{~L} 14=240.5 \mathrm{~kW}, \mathrm{~L} 15=215 \mathrm{~kW}$, L16 $=132 \mathrm{~kW}, \mathrm{~L} 17=75 \mathrm{~kW}, \mathrm{~L} 18=30.3 \mathrm{~kW}, \mathrm{~L} 19=20 \mathrm{~kW}$, $\mathrm{L} 20=19 \mathrm{~kW}, \mathrm{~L} 21=18 \mathrm{~kW}$ and L22 $=18 \mathrm{~kW}$. Considered $\mathrm{a}$ function for the same number of $\alpha$ where $\alpha$ will be either 0 or 1 as shown in (2) and $f(x)$ will contain $n$ numbers of $\alpha$ as shown in (3). 
$f: \alpha \rightarrow\{0,1\}^{n}$

$x \rightarrow f(x)=\left(\alpha_{1}, \alpha_{2}, \alpha_{3}, \ldots \ldots \ldots, \alpha_{n}\right)$

The function $f(x)$ from (3) is to be determined by mixedinteger linear programming as some of the variables $(\mathrm{Li})$ of the connectable load set L are constrained to be integers, while other variables are allowed to be non-integers [32]. Function $f(x)$ will be used to find out the possible combinations of load set L, so that the error between the summation of output load set Lo and the generated energy $G$ will be equal to or close to zero as shown in (4) and the amount of error will not be negative as shown in (5), because the summation of output load set Lo will never be more than the net solar PV generated energy.

$\min \left(G-\sum_{i=1}^{n} \alpha_{i} L_{i}\right)$

$G-\sum \alpha_{i} L_{i} \geq 0$

Here, $\mathrm{G}=$ current energy generation $(\mathrm{kW})=0 \sim 325 \mathrm{~kW}$, as this case has been analyzed for $325 \mathrm{~kW}$ peak capacity. The output of this process operation will provide the expected loads to be connected with the solar PV generated power to feed, by providing the output load set Lo which has been shown in (6).

$L_{o}=\left(\alpha_{1} L_{1}, \alpha_{2} L_{2}, \alpha_{3} L_{3}, \ldots \ldots \ldots, \alpha_{n} L_{n}\right)$

By getting the value of $\alpha$ as 0 or 1 , the process will decide the corresponding load will be kept or not in the output load set Lo. The simulation of this process operation provides different types of results for different values of $G$. As the value of $G$ will change with time depending on weather condition and solar irradiation, for each and every value of $G$, there are lots of different output load combination Lo is possible. For example, when $\mathrm{G}=208 \mathrm{~kW}$, The MATLAB simulation provides different 226 possible combinations for Lo to be connected with the solar generated power $\mathrm{G}$ for exact zero error or $100 \%$ utilization of solar PV generated energy as shown in (7) or (8).

$G-\sum \alpha_{i} L_{i}=0$

$\sum L_{o}=\sum \alpha_{i} L_{i}=G=208$

The output Lo can be combined of different number of loads. Some sample of output combination Lo combining different number of loads from MATLAB [33] simulation have been presented in (9) to (13). Here, (9), (10), (11), (12) and (13) presents the possible combination with 3, 4, 5, 6 and 7 loads respectively.

$L_{o}=\left(L_{4}, L_{16}, L_{19}\right)$

$L_{o}=\left(L_{2}, L_{6}, L_{9}, L_{16}\right)$

$L_{o}=\left(L_{2}, L_{4}, L_{6}, L_{17}, L_{20}\right)$
TABLE I

Lo With All Possible Combinations of 4 LOAds FOR G $=208 \mathrm{KW}$

\begin{tabular}{llllllll}
\multicolumn{3}{c}{ Lo Load Sets } & \multicolumn{4}{c}{ Lo Load Values (in kW) } \\
\hline $\mathrm{L}_{2}$ & $\mathrm{~L}_{6}$ & $\mathrm{~L}_{9}$ & $\mathrm{~L}_{16}$ & 31 & 27 & 18 & 132 \\
$\mathrm{~L}_{2}$ & $\mathrm{~L}_{6}$ & $\mathrm{~L}_{16}$ & $\mathrm{~L}_{21}$ & 31 & 27 & 132 & 18 \\
$\mathrm{~L}_{2}$ & $\mathrm{~L}_{6}$ & $\mathrm{~L}_{16}$ & $\mathrm{~L}_{22}$ & 31 & 27 & 132 & 18 \\
$\mathrm{~L}_{2}$ & $\mathrm{~L}_{7}$ & $\mathrm{~L}_{16}$ & $\mathrm{~L}_{19}$ & 31 & 25 & 132 & 20 \\
$\mathrm{~L}_{5}$ & $\mathrm{~L}_{9}$ & $\mathrm{~L}_{12}$ & $\mathrm{~L}_{16}$ & 54 & 18 & 4 & 132 \\
$\mathrm{~L}_{5}$ & $\mathrm{~L}_{12}$ & $\mathrm{~L}_{16}$ & $\mathrm{~L}_{21}$ & 54 & 4 & 132 & 18 \\
$\mathrm{~L}_{5}$ & $\mathrm{~L}_{12}$ & $\mathrm{~L}_{16}$ & $\mathrm{~L}_{22}$ & 54 & 4 & 132 & 18 \\
$\mathrm{~L}_{6}$ & $\mathrm{~L}_{7}$ & $\mathrm{~L}_{8}$ & $\mathrm{~L}_{16}$ & 27 & 25 & 24 & 132 \\
\hline \hline
\end{tabular}

TABLE II

VALUES OF G WITH ERRORS FOR $1 \mathrm{KW}$ SAMPLE STEPS

\begin{tabular}{rllll}
\hline \hline \multicolumn{1}{c}{$\mathrm{G}$} & \multicolumn{1}{c}{$\mathrm{L}_{\mathrm{O}}$} & \multicolumn{1}{c}{ Error } & Utilization & Wastage \\
& & & & \\
\hline $1 \mathrm{KW}$ & $0 \mathrm{KW}$ & $1.00 \mathrm{KW}$ & $0 \%$ & $100 \%$ \\
$2 \mathrm{KW}$ & $0 \mathrm{KW}$ & $2.00 \mathrm{KW}$ & $0 \%$ & $100 \%$ \\
$3 \mathrm{KW}$ & $0 \mathrm{KW}$ & $3.00 \mathrm{KW}$ & $0 \%$ & $100 \%$ \\
$5 \mathrm{KW}$ & $4 \mathrm{KW}$ & $1.00 \mathrm{KW}$ & $80 \%$ & $20 \%$ \\
$6 \mathrm{KW}$ & $4 \mathrm{KW}$ & $2.00 \mathrm{KW}$ & $66.67 \%$ & $33.33 \%$ \\
$7 \mathrm{KW}$ & $4 \mathrm{KW}$ & $3.00 \mathrm{KW}$ & $57.14 \%$ & $42.86 \%$ \\
$8 \mathrm{KW}$ & $4 \mathrm{KW}$ & $4.00 \mathrm{KW}$ & $50 \%$ & $50 \%$ \\
$9 \mathrm{KW}$ & $4 \mathrm{KW}$ & $5.00 \mathrm{KW}$ & $44.44 \%$ & $55.56 \%$ \\
$10 \mathrm{KW}$ & $4 \mathrm{KW}$ & $6.00 \mathrm{KW}$ & $40 \%$ & $60 \%$ \\
$11 \mathrm{KW}$ & $4 \mathrm{KW}$ & $7.00 \mathrm{KW}$ & $36.36 \%$ & $63.64 \%$ \\
$13 \mathrm{KW}$ & $12 \mathrm{KW}$ & $1.00 \mathrm{KW}$ & $92.31 \%$ & $7.69 \%$ \\
$14 \mathrm{KW}$ & $12 \mathrm{KW}$ & $2.00 \mathrm{KW}$ & $85.71 \%$ & $14.29 \%$ \\
$15 \mathrm{KW}$ & $12 \mathrm{KW}$ & $3.00 \mathrm{KW}$ & $80 \%$ & $20 \%$ \\
$26 \mathrm{KW}$ & $25 \mathrm{KW}$ & $1.00 \mathrm{KW}$ & $96.15 \%$ & $3.85 \%$ \\
\hline \hline
\end{tabular}

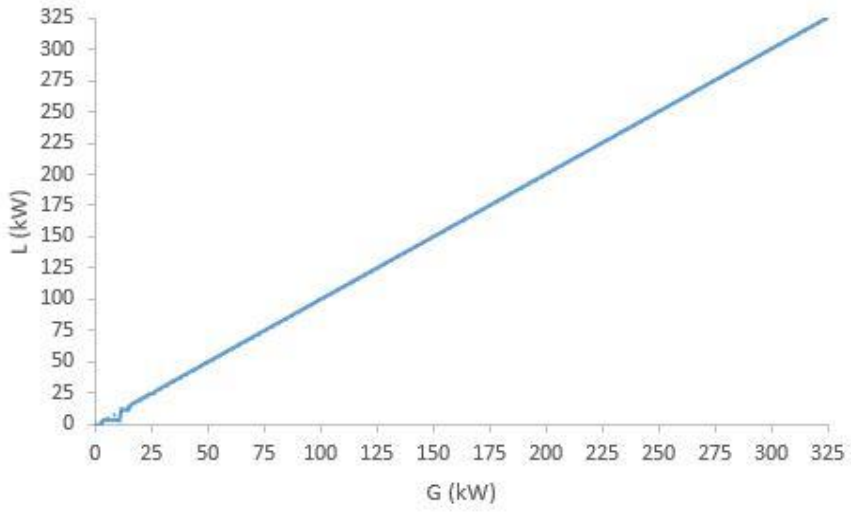

Fig. 11. Graph of MATLAB simulation result for $\mathrm{G}=0 \sim 325 \mathrm{~kW}$ with $1 \mathrm{~kW}$ sample steps.

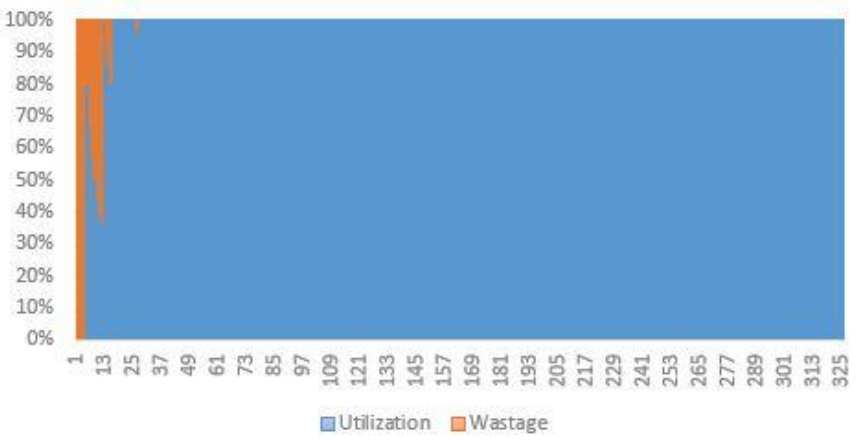

Fig. 12. Energy Utilization and Wastage.

$L_{o}=\left(L_{2}, L_{4}, L_{5}, L_{7}, L_{8}, L_{9}\right)$ 


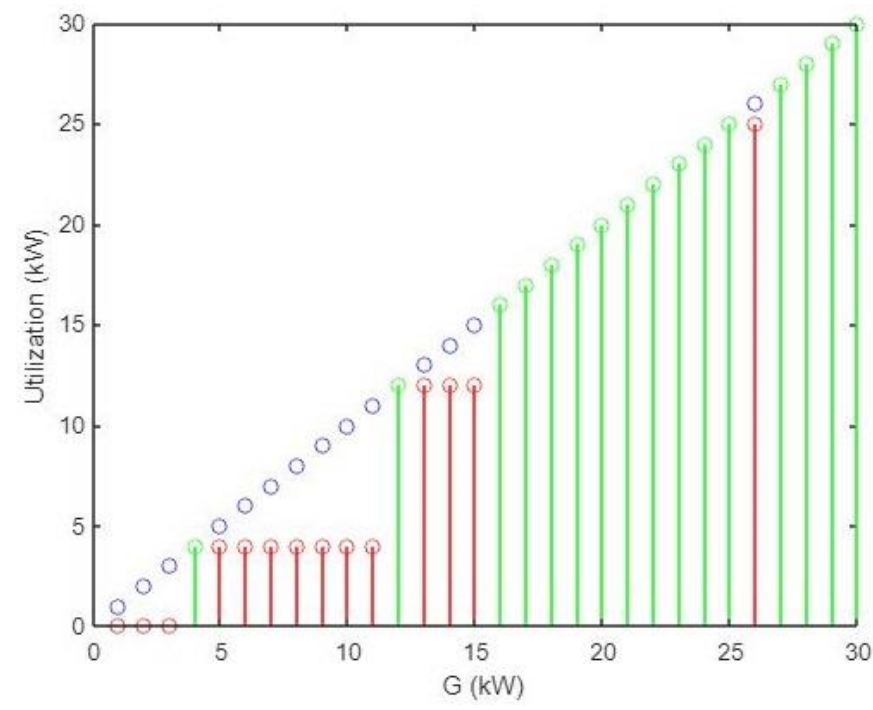

Fig. 13. Energy Utilization MATLAB simulation result for $\mathrm{G}=0 \sim 30 \mathrm{~kW}$ with for $1 \mathrm{~kW}$ sample steps.

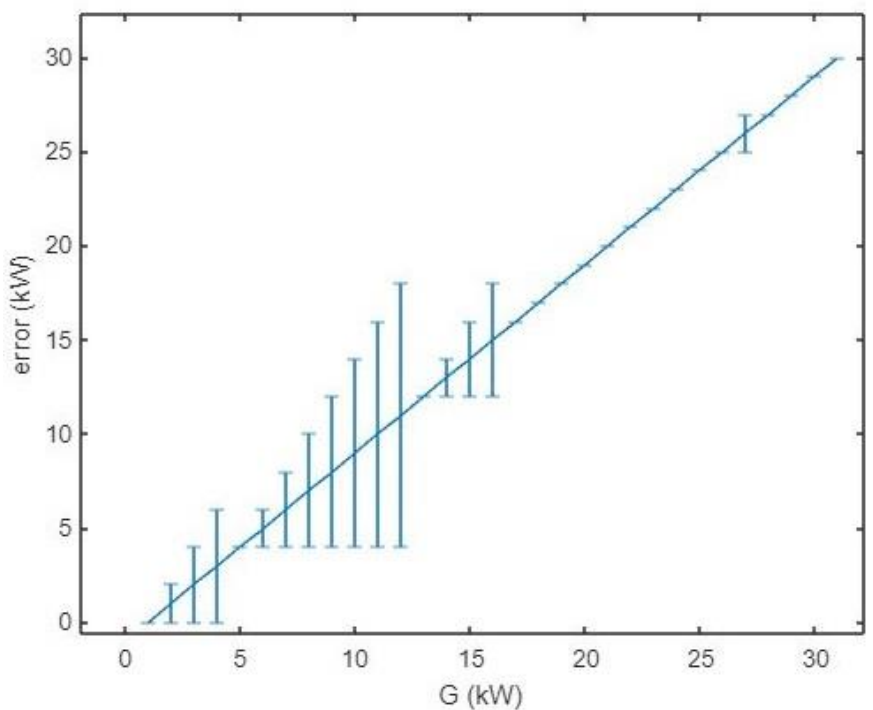

Fig. 14. Error or Energy Wastage MATLAB simulation result for $\mathrm{G}=0 \sim 30$ $\mathrm{kW}$ with for $1 \mathrm{~kW}$ sample steps.

$L_{o}=\left(L_{2}, L_{4}, L_{5}, L_{6}, L_{8}, L_{11}, L_{12}\right)$

The summation of load set Lo is exactly equal to $\mathrm{G}=208$ which has been presented in (14), (15), (16), (17) and (18) for (9), (10), (11), (12) and (13) respectively.

$\sum L_{o}=56+132+20=208=G$

$\sum L_{o}=31+27+18+132=208=G$

$\sum L_{o}=31+56+27+75+19=208=G$

$\sum L_{o}=31+56+54+25+24+18=208=G$

$\sum L_{o}=31+56+54+27+24+12+4=208=G$

$100 \%$ utilization of solar PV generated energy with any specific number of loads to be connected, also possible with

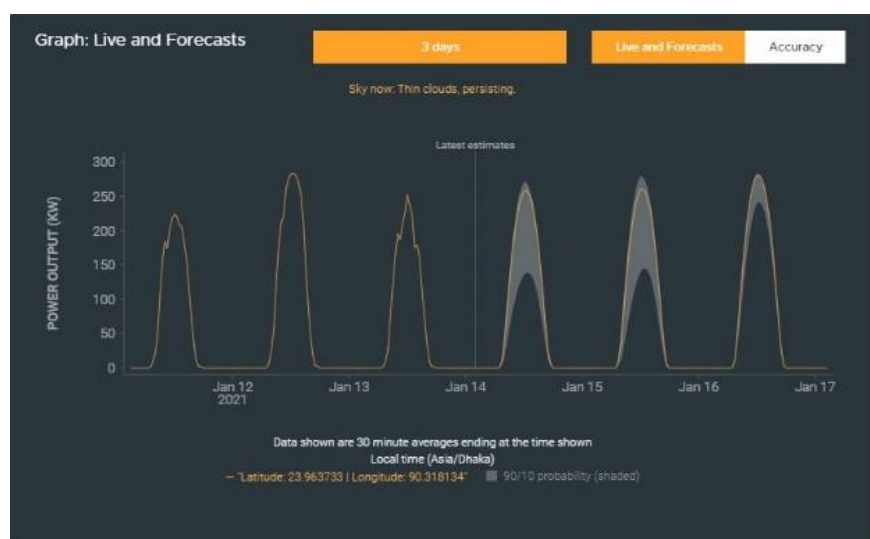

Fig. 15. Solcast simulation results of supply prediction showing live and forecasts for 3 days.

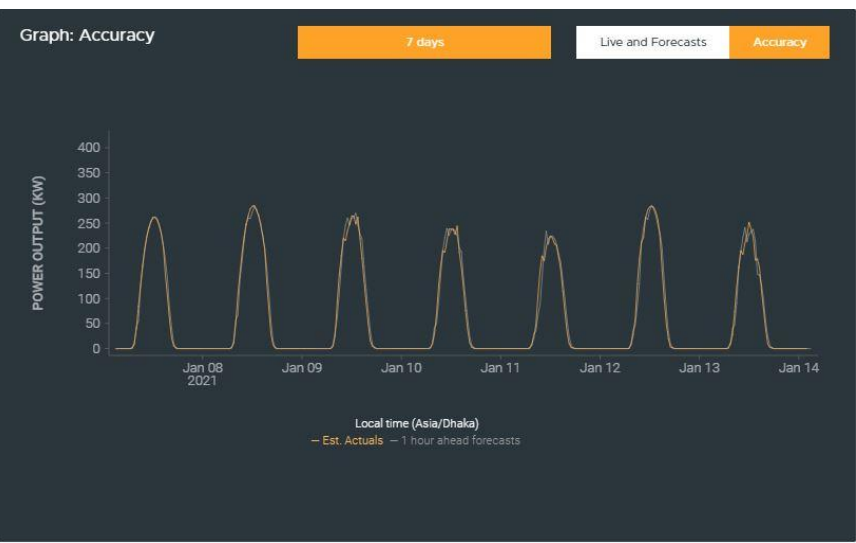

Fig. 16. Solcast simulation results of supply prediction showing accuracy report for 7 days.

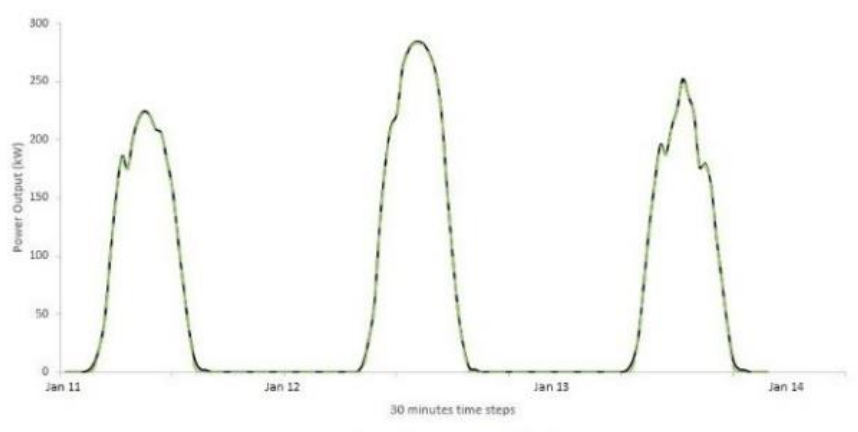

- Generatea Enetgr - - venised tnerg

Fig. 17. MATLAB simulation for Solcast data showing Generated Energy and Utilized Energy.

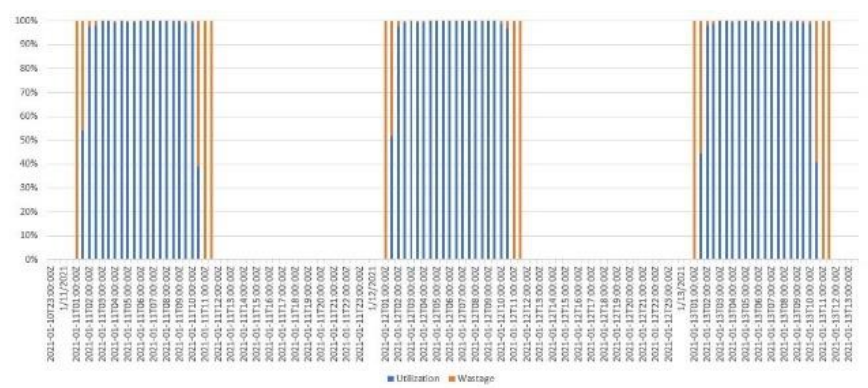

Fig. 18. MATLAB simulation for Solcast data showing Energy Utilization and Wastage analysis.

different combinations. Like, for total 4 loads, there are 8 different combinations are possible with exact zero error, which 
has been shown in Table 1. As the $100 \%$ solar PV generated power utilization is possible with more than one combination for $\mathrm{G}=209 \mathrm{~kW}$ as shown in Table 1, the automation unit will utilize this flexibility to select the loads based on the load forecasting data. The MATLAB simulation result for $1 \mathrm{~kW}$ sample steps shows that, the $100 \%$ utilization is possible for every single value of $\mathrm{G}$ with the existing 22 loads, when the value of $\mathrm{G}$ is higher than $26 \mathrm{~kW}$. The Fig. 11 is the graph of the total utilized energy, $\mathrm{L}$ with respect to the total generated energy, G, which shows that the $100 \%$ utilization is not possible only for the low generation of power from solar PV unit. Fig. 12 shows the percentage of total energy utilization and total energy wastage for $\mathrm{G}=0 \sim 325 \mathrm{~kW}$ in $1 \mathrm{~kW}$ sample steps.

When the total generated energy is below $27 \mathrm{~kW}$, energy wastage will occur for total 14 cases. Those are $\mathrm{G}=1 \mathrm{~kW}, 2$ $\mathrm{kW}, 3 \mathrm{~kW}, 5 \mathrm{~kW}, 6 \mathrm{~kW}, 7 \mathrm{~kW}, 8 \mathrm{~kW}, 9 \mathrm{~kW}, 10 \mathrm{~kW}, 11 \mathrm{~kW}, 13$ $\mathrm{kW}, 14 \mathrm{~kW}, 15 \mathrm{~kW}$, and $26 \mathrm{~kW}$. Here, the highest amount of error or energy wastage will occur for $\mathrm{G}=11 \mathrm{~kW}$ which is error $=7 \mathrm{~kW}$ and, the lowest amount of error or energy wastage will occur for $\mathrm{G}=1 \mathrm{~kW}, 5 \mathrm{~kW}, 13 \mathrm{~kW}$, and $26 \mathrm{~kW}$ which is error $=$ $1 \mathrm{~kW}$. The MATLAB simulation result for $\mathrm{G}=0 \sim 30 \mathrm{~kW}$, where for $\mathrm{G}=4 \mathrm{~kW}, 12 \mathrm{~kW}, 16 \mathrm{~kW}, 17 \mathrm{~kW}, 18 \mathrm{~kW}, 19 \mathrm{~kW}, 20$ $\mathrm{kW}, 21 \mathrm{~kW}, 22 \mathrm{~kW}, 23 \mathrm{~kW}, 24 \mathrm{~kW}, 25 \mathrm{~kW}, 27 \mathrm{~kW}, 28 \mathrm{~kW}, 29$ $\mathrm{kW}$, and $30 \mathrm{~kW}$, the $100 \%$ energy utilization is possible with the considered load set, and for the other values of G, the $100 \%$ utilization is not possible, which has been presented in Fig. 13. The error bar graph has been shown in Fig. 14. All the values of $\mathrm{G}$ with errors have been presented in Table 2 with their most optimized load combinations for achieving the lowest amount of error as found by MATLAB software [33] and their total amount of utilized and wasted energy with the percentage of energy utilization and wastage for $1 \mathrm{~kW}$ sample steps.

Appling MATLAB simulation result for Solcast API Toolkit [34] simulation data for a demo location of Latitude: 23.963733 and Longitude: 90.318134 rooftop solar PV site with $325 \mathrm{~kW}$ peak capacity, south facing azimuth 180 degrees, horizontal tilt 23 degrees, a real time scenario can be analyzed. Fig. 15 and Fig. 16 represents the Solcast simulation results of supply prediction, where Fig. 15 presents the live power output (for the date of January 14 of 2021), actual power output for last 3 days (from January 11 of 2021 to January 13 of 2021), and the predicted power output for next 3 days (from January 16 of 2021 to January 16 of 2021) with $90 / 10$ probability.

Fig. 16 presents the supply prediction accuracy for last 7 days (from January 7 of 2021 to January 13 of 2021). The live and forecasts graph of Fig. 15 shows 3 hours ahead supply prediction forecasts and the 7 days accuracy report of Fig. 16 has been generated for 1 hour ahead supply prediction forecasts. Fig. 17 and Fig. 18 represents the MATLAB simulation results for Solcast simulation data. Fig. 17 shows the total generated energy and the total utilized energy of the roof top solar PV system, where it can be seen that total utilized energy line almost follows the total generated energy line. At the morning and evening, when the energy generation is relatively low, their might have some wastage. From the simulated result maximum amount of wasted energy in last 3 days (from January 11 of 2021 to January 13 of 2021) was $6.2543 \mathrm{~kW}$ at the evening of 11 January, 2021 when the value of $\mathrm{G}$ was $10.2543 \mathrm{~kW}$. So, the

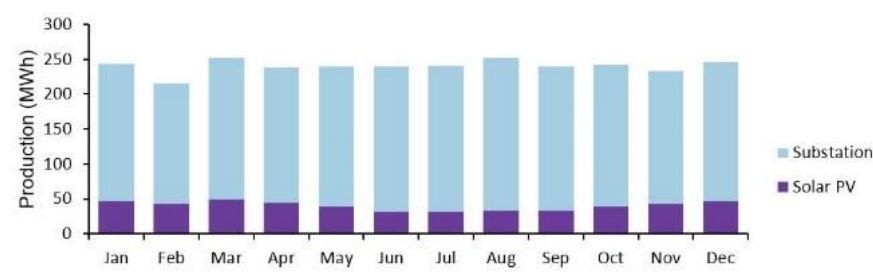

Fig. 19. Annual power generation from solar PV system and utilization of grid power.

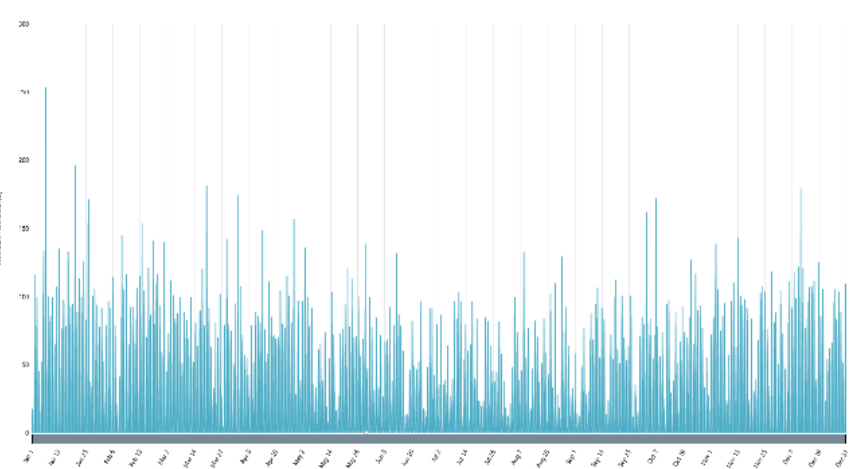

Fig. 20. Homer software renewable penetration analysis data of the proposed system.

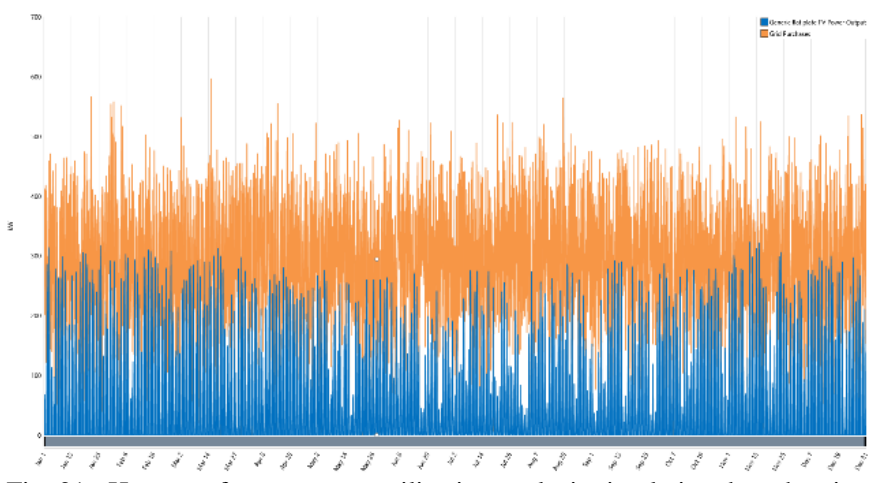

Fig. 21. Homer software energy utilization analysis simulation data showing annual data.

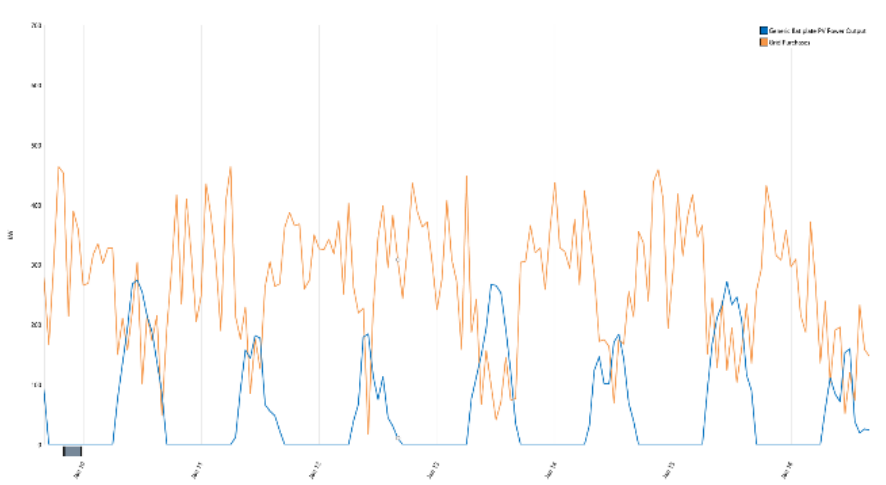

Fig. 22. Homer software energy utilization analysis simulation data showing everyday scenario.

$39.0080259 \%$ generates energy has been utilized and $60.9919741 \%$ generates energy has been wasted at evening time. The minimum amount of wasted energy was $0.0026 \mathrm{~kW}$ at the mid-day of 13 January, 2021 when the value of G was $237.3026 \mathrm{~kW}$. So, the $99.99890435 \%$ generates energy has been utilized which is equivalent to $100 \%$ and $0.001095647 \%$ generates energy has been wasted which is equivalent to $0 \%$ at mid-day. Everyday, at morning and evening time, the solar PV energy generation remains below $4 \mathrm{~kW}$. At that time, the $100 \%$ 
generated energy had been wasted as there is no load sized under $4 \mathrm{~kW}$ in the considered load set. Fig. 18 represents the energy wastage in the morning and evening times and the almost $100 \%$ utilization in the mid-day.

\section{OVERALl SySTEM ANALysis}

In all pharmaceutical manufacturing facilities, to ensure the acceptance of end products all over the world, the compliance with some international regulatory authority guidelines is been ensured. As a result, all existing facilities are utilizing online UPS system to ensure the uninterruptable power to production machineries. Utilizing the existing DC power storage units from those online UPS systems, a large amount of solar PV system installation cost can be reduced. In that case, a sophisticated energy trafficking system will be required which will be performed by the proposed automation system to ensure the reliability. The basic system to feed the pharmaceutical manufacturing facility loads combining the grid power and backup generator. Here the problem is, at the time of load shedding from the grid power, the backup generator takes a startup delay for about 5 10 minutes on average. So, the uninterruptable power supply to the load is not possible. As it is a core requirement of most of the international regulatory authority guidelines to maintain the uninterruptable power supply to the load, all pharmaceutical manufacturing facilities contain online UPS system with at least one hour power backup capacity. The traditional hybrid system includes solar PV energy generation system containing in-built DC power storage system for at least 3 days power backup capacity. In this traditional hybrid system, the total load of the manufacturing machineries can be operated using renewable power if any major climate constrains does not occur. For worst case scenario, both the grid power and the backup generator power can be utilized to maintain the uninterruptable power supply to the load. The addressed limitation here is the installation cost of the in-built DC power storage system for solar PV system which is high. This limitation can be overcome by utilizing the existing DC storage units of online UPS directly for solar PV unit generated DC power. In that case an efficient energy trafficking system will be required to ensure the $100 \%$ utilization of solar PV generated renewable power, which will be performed by the proposed automation system as discussed in the previous section.

The proposed hybrid system renewable penetration analysis has been presented in Fig. 19 and Fig. 20. Fig. 19 is the total energy supplied to the considered pharmaceuticals industry manufacturing facility loads where the fully utilized total energy generation from the $325 \mathrm{~kW}$ off-grid solar PV unit as well as the total amount of energy utilization from grid which was required by the production machineries load for each month of a sample year inside the considered lifetime of the proposed hybrid system. Fig. 20 shows the percentage of renewable penetration throughout the year which is the ratio between the total renewable electrical power output of the renewable source in $\mathrm{kW}$ and the total electrical load served in $\mathrm{kW}$ for each time step.

The simulation result shows the maximum value of renewable penetration that occurs during the year. In Fig. 21,
TABLE III

TYPICAL PHARMACEUTICALS MANUFACTURING FACILITY LOAD DISTRIBUTION

\begin{tabular}{|c|c|c|c|c|}
\hline & Overall & $\begin{array}{l}\text { Plug Loads } \\
\text { and } \\
\text { Processes }\end{array}$ & Lighting & $\begin{array}{c}\text { Heating, } \\
\text { Ventilation } \\
\text { and Air } \\
\text { Conditioning }\end{array}$ \\
\hline Total & $100 \%$ & $25 \%$ & $10 \%$ & $65 \%$ \\
\hline $\begin{array}{l}\text { Laboratory } \\
\text { Environment }\end{array}$ & $30 \%$ & $\begin{array}{l}\text { Microscopes, } \\
\text { Centrifuges, } \\
\text { Electric } \\
\text { Mixers, } \\
\text { Analysis } \\
\text { Equipment, } \\
\text { Sterilization } \\
\text { Processes, } \\
\text { Incubators }\end{array}$ & $\begin{array}{l}\text { Task and } \\
\text { Overhead } \\
\text { Lighting }\end{array}$ & $\begin{array}{l}\text { Clean Rooms, } \\
\text { Fume Hoods, } \\
\text { AHU, MAU, } \\
\text { Chilled Water } \\
\text { System, Hot } \\
\text { Water System }\end{array}$ \\
\hline Comfort Zone & $10 \%$ & $\begin{array}{l}\text { Office } \\
\text { Equipment }\end{array}$ & $\begin{array}{l}\text { Task, } \\
\text { Overhead } \\
\text { and } \\
\text { Outdoor } \\
\text { Lighting }\end{array}$ & $\begin{array}{l}\text { Space } \\
\text { Heating, } \\
\text { Cooling, } \\
\text { Ventilation }\end{array}$ \\
\hline $\begin{array}{l}\text { Bulk } \\
\text { Manufacturing } \\
\text { Area }\end{array}$ & $35 \%$ & $\begin{array}{l}\text { Incubators, } \\
\text { Sterilization } \\
\text { Processes, } \\
\text { Centrifuges, } \\
\text { Dryers, } \\
\text { Separation } \\
\text { Processes }\end{array}$ & $\begin{array}{l}\text { Task and } \\
\text { Overhead } \\
\text { Lighting }\end{array}$ & $\begin{array}{l}\text { Clean Rooms, } \\
\text { Fume Hoods, } \\
\text { AHU, MAU, } \\
\text { Chilled Water } \\
\text { System, Hot } \\
\text { Water System } \\
\text { and Steam } \\
\text { System }\end{array}$ \\
\hline $\begin{array}{l}\text { Formulation, } \\
\text { Packaging and } \\
\text { Filling Area }\end{array}$ & $15 \%$ & $\begin{array}{l}\text { Mixers, } \\
\text { Motors }\end{array}$ & $\begin{array}{l}\text { Mostly } \\
\text { Overhead, } \\
\text { Some } \\
\text { Task }\end{array}$ & $\begin{array}{l}\text { Particle } \\
\text { Control } \\
\text { Ventilation }\end{array}$ \\
\hline Warehouses & $5 \%$ & $\begin{array}{l}\text { Forklift, } \\
\text { Water } \\
\text { Heating }\end{array}$ & $\begin{array}{l}\text { Mostly } \\
\text { Overhead } \\
\text { Lighting }\end{array}$ & $\begin{array}{l}\text { Space } \\
\text { Heating, } \\
\text { Refrigeration }\end{array}$ \\
\hline Miscellaneous & $5 \%$ & & & \\
\hline
\end{tabular}

the Homer software simulation data for energy utilization analysis has been presented where both renewable power generation from $325 \mathrm{~kW}$ off-grid solar PV unit and energy utilization from grid has been showed. Fig. 22 is the annual data for one sample year inside the considered lifetime of the proposed hybrid system which is 25 years. Fig. 22 shows the everyday scenario for some sample days from the month of January, which presents that at the time of utilizing the renewable power, the grid power utilization decreases as required by the load. The system analysis simulations work has been performed with Homer software [35] which applies NASA prediction of Worldwide Energy Resource (POWER) database for solar Global Horizontal Irradiance (GHI) and Clearness Index to simulate the probable solar PV energy generation throughout the year at the considered demo location of Latitude: 23.963733 and Longitude: 90.318134 rooftop solar PV site. The ideal parameters have been used for all simulation as suggested by Homer software. As the total amount of the considered facility load which is connected with the proposed hybrid system is higher than the peak capacity of the renewable source which is $325 \mathrm{~kW}$ most of the time for this considered test scenario, the pharmaceutical facility is taking the grid power after utilizing $100 \%$ of the renewable power most of the time. 


\section{Feasibility StUdy For Pharmaceuticals}

A typical load distribution scenario in a pharmaceutical industry has been presented in Table 3 [36]. From Table 3, it has been presented that, in a pharmaceutical industry, most of the electrical power is been used for Heating, Ventilation and Air Conditioning (HVAC) applications which is $65 \%$ of the total load. HVAC system maintains the environmental parameters like temperature, relative humidity, differential air pressure, air filtration etc. in the classified clean room environment of the pharma manufacturing areas. No online UPSs are been used with these HVAC loads as the environmental parameters cannot be changed instantly after the power failure at the time of load shedding from the grid. The central backup generators are been assigned to start automatically within few minutes and the HVAC equipment starts operating as soon as the backup power is stablished. In these few minutes, the environmental parameters do not go out of limit for most of the cases. Though, the automation unit of HVAC control system which is known as building management system (BMS), contains their own online UPS system which is very low in size with respect to other HVAC loads. In some cases, the HVAC loads are been required to be run uninterruptedly due to the sensitive product requirements. For those cases, all the high loads of HVAC equipment also contain online UPS system. $10 \%$ of the overall load is been required for lighting purpose, which also do not require any online UPSs. Few emergency lights in each area contains online UPS service in pharmaceuticals industry. Plug loads and processes consumes $25 \%$ of the total load. In this section, some loads which are in comfort zones, warehouses and miscellaneous areas, do not require online UPSs in most of the pharmaceutical industry applications. The laboratory environment, bulk, manufacturing area, formulation, packaging and filling areas are very important and sensitive areas in any pharma industry, where each pharma maintains the $100 \%$ uninterrupted power supply utilizing online UPS systems.

All the pharmaceutical manufacturing facilities are been located in commercial zone where the availability of space for installing a solar PV energy generation system is low. Even, the roof top areas are also been occupied for chiller plant, cooling towers, helipads, etc. The rest of the area can be utilized for generating solar power, but in that case the total size of the solar power plant will not be enough for feeding the total loads of a pharmaceuticals manufacturing facility. In that case, the utilization of grid power is the most feasible option. The backup generator is required to supply power to the load at the time of load shedding from the grid. Due to the weather dependency of solar PV power generation system, a DC power storage facility is required to ensure the reliability which involves additional space, cost and operational maintenance issues. As, all the online UPS systems for important and sensitive plug loads and processes already contains DC power storage facilities, utilizing those facilities decreases the installation cost of a solar PV power generation system by reducing the cost of DC power storage unit to zero. In that case, all the facility loads which are equal or less than the rated capacity of the solar PV system needs to be connected to the solar PV system through a sophisticated automation system which will perform efficient energy trafficking to maintain the $100 \%$ utilization of
TABLE IV

COMPARISON BETWEen THE TWO SYSTEMS WHERE ONE IS WITH ENERgY TRAFFICKING AND ANOTHER ONE IS WITHOUT ENERGY TRAFFICKING

\begin{tabular}{|c|c|c|c|}
\hline & Morning & Mid-day & Evening \\
\hline Generated Energy & $21.46 \mathrm{~kW}$ & $224.17 \mathrm{~kW}$ & $35.29 \mathrm{~kW}$ \\
\hline $\begin{array}{l}\text { Utilized Energy with Energy } \\
\text { Trafficking }\end{array}$ & $21.00 \mathrm{~kW}$ & $224.00 \mathrm{~kW}$ & $35.00 \mathrm{~kW}$ \\
\hline $\begin{array}{l}\text { Utilized Energy without } \\
\text { Energy Trafficking }\end{array}$ & $0.00 \mathrm{~kW}$ & $144.20 \mathrm{~kW}$ & $0.00 \mathrm{~kW}$ \\
\hline $\begin{array}{l}\text { Error with Energy } \\
\text { Trafficking }\end{array}$ & $0.46 \mathrm{~kW}$ & $0.17 \mathrm{~kW}$ & $0.29 \mathrm{~kW}$ \\
\hline $\begin{array}{l}\text { Error without Energy } \\
\text { Trafficking }\end{array}$ & $21.46 \mathrm{~kW}$ & $79.97 \mathrm{~kW}$ & $35.29 \mathrm{~kW}$ \\
\hline $\begin{array}{l}\text { Utilization with Energy } \\
\text { Trafficking }\end{array}$ & $97.85 \%$ & $99.92 \%$ & $99.19 \%$ \\
\hline $\begin{array}{l}\text { Utilization without Energy } \\
\text { Trafficking }\end{array}$ & $0.00 \%$ & $64.33 \%$ & $0.00 \%$ \\
\hline $\begin{array}{l}\text { Wastage with Energy } \\
\text { Trafficking }\end{array}$ & $2.16 \%$ & $0.08 \%$ & $0.81 \%$ \\
\hline $\begin{array}{l}\text { Wastage without Energy } \\
\text { Trafficking }\end{array}$ & $100.00 \%$ & $35.68 \%$ & $100.00 \%$ \\
\hline
\end{tabular}

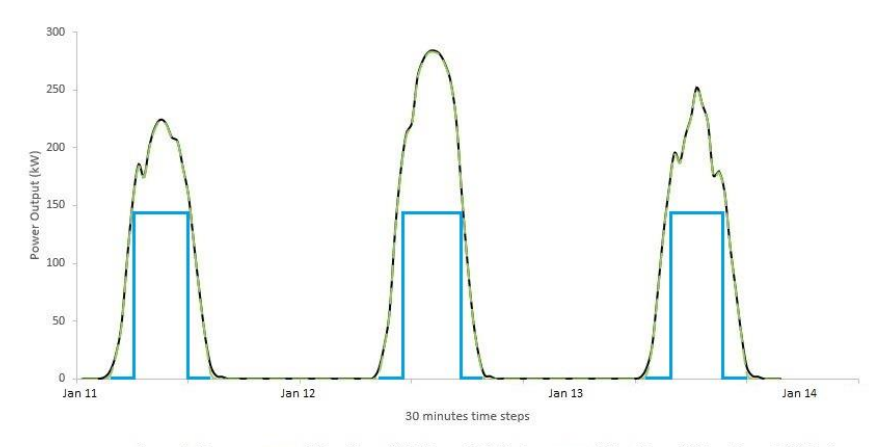

Fig. 23. Comparison between Utilized Energy with Energy Trafficking and Utilized Energy without Energy Trafficking with respect to the Total Generated Energy.

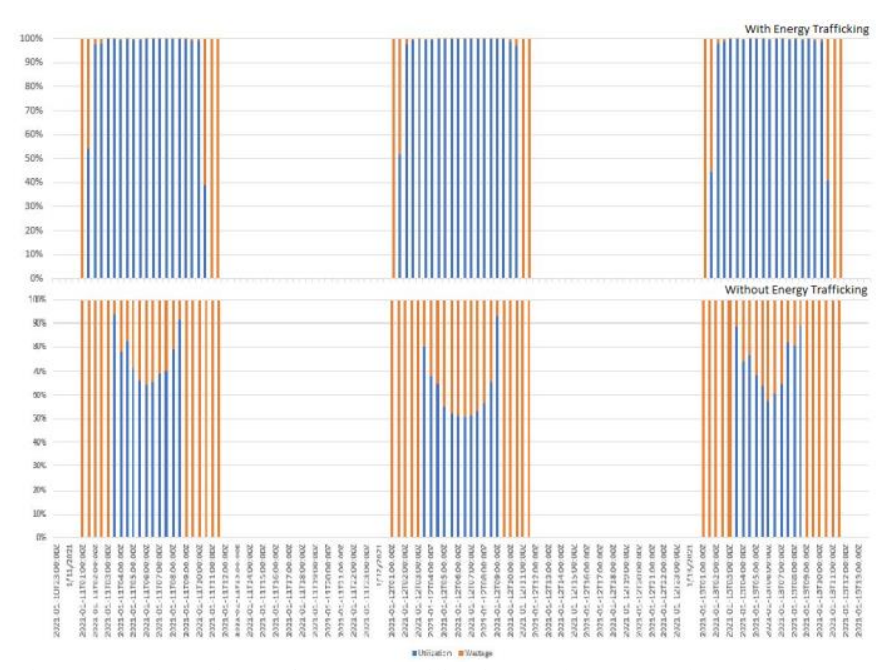

Fig. 24. Comparison of Energy Utilization and Wastage between the two systems where one is with Energy Trafficking and another one is without Energy Trafficking.

renewable power and ensure the reliability. The installation of this proposed system includes a comparatively high installation cost, but it will be cost efficient considering the full lifecycle of the project as it will help to reduce the purchase of grid power over time. 


\section{RESUlt ANALYSIS}

The considered $325 \mathrm{~kW}$ solar PV system is unable to produce electricity up to its full capacity throughout the year due to weather dependency. In the considered load set of pharmaceuticals manufacturing facility contains a maximum load size of $266 \mathrm{~kW}$, but based on the Global Horizontal Irradiance (GHI) data from both Solcast and NASA prediction of worldwide energy resource reflects that the generated energy from a $325 \mathrm{~kW}$ solar PV system in the considered location will be under $266 \mathrm{~kW}$ in most of the time. Considering the highest load below $200 \mathrm{~kW}$ to be connected with the solar PV system which is $144.2 \mathrm{~kW}$ as a traditional fixed load renewable energy system, the comparison between the proposed hybrid renewable energy system with energy trafficking and the traditional hybrid renewable energy system with fixed load or without energy trafficking has been presented in Table 4 as well as Fig. 23 and Fig. 24.

Comparing the fixed load system with the Solcast, MATLAB and Homer simulation data of the proposed system, it can be seen that the generated energy will be utilized only when the value of the generated energy will be greater than the value of the connected load size, as the in-built DC storage facility has been excluded in this scenario for cost minimization. Table 4 shows that at the sample time in morning, when the amount of the generated energy is $21.46 \mathrm{~kW}$, the proposed system has already started utilizing the solar PV generated energy and the percentage of utilization is already $97.84462 \%$, but the fixed load system has not started utilizing the solar PV generated energy as the value of the generated energy is still less than the connected load value. At a sample time in mid-day, when the solar PV generated energy is $224.17 \mathrm{~kW}$ which is higher than the load size of the fixed load system, both of the system has started utilizing the solar PV generated energy. But, the utilized energy of the proposed system is $224.00 \mathrm{~kW}$ which is a $99.92283 \%$ utilization where the utilized energy of the fixed load system is still same as the connected load size $144.2 \mathrm{~kW}$ which is only $64.32532 \%$ utilization. At a sample time in evening, when the amount of the generated energy is again decreased to $35.29 \mathrm{~kW}$, the proposed system is still utilizing the solar PV generated energy and the percentage of utilization is $99.18836 \%$, but the fixed load system has already stopped utilizing the solar PV generated energy as the value of the generated energy is again less than the connected load value.

The graph of Fig. 23 presents the comparison between utilized energy with energy trafficking and utilized energy without energy trafficking with respect to the total generated energy, which shows that the energy wastage of fixed load system is always higher than the energy wastage of proposed system which also reflects the sample data presented in Table 4. Fig. 23 also presents that when the generated energy is higher than the fixed load value, the utilized energy is always equal to the fixed load value and the extra amount of generated energy is been wasted. But for the proposed system, the energy wastage is always low. Fig.24 presents the comparison of the percentage of Energy Utilization between the two systems where one is with Energy Trafficking and another one is without Energy Trafficking. It also presents that the solar PV generated electricity utilization is always higher in the proposed system than the fixed value system. The solar PV generated electricity wastage is also less in the proposed system than the fixed value system.

There are some added advantages of utilizing and automation system for an off-grid solar PV energy generation unit in pharmaceutical industry applications. An automation system can perform all the required activities with a zero to minimum supervision. It also contains all the required features for international pharmaceuticals regulations as continuous monitoring and data archiving is required to comply with international regulations. A pharmaceutical manufacturing facility must have to be ensured by $100 \%$ uninterrupted power supply. Frequent shifting of power sources is not acceptable in a validated pharmaceuticals environment. Combined operation of solar generated DC power and incoming AC power inside an online UPS system will have no effect of load side. The Load will have $100 \%$ uninterrupted power supply as before after utilizing solar power. In this way, most of the solar generated power can be utilized. Sophisticated energy supply prediction and load demand prediction based on archived historical data on both generation end and load end can be used for ensuring reliability. As each and every pharmaceuticals industry contains online UPS system for most of its critical units, if the battery bank of those online UPSs can directly be utilized for storing solar power and feeding critical loads, it will be both cost efficient and almost $100 \%$ solar generated power can be utilized.

\section{CONCLUSION}

From the analysis it has been observed that the utilization of solar PV generated energy is better in the proposed system for pharmaceutical company than a traditional integrated renewable energy system. In most of the traditional integrated renewable energy system, the load set usually been shifted to different energy sources based on the availability of the electrical energy in different sources like renewable, generator, or grid power. In that case, when the generated energy by the renewable sources is less than the connected load set, the load set is shifted to another source based on priority. As a result, the generated energy of the renewable sources though it is low is wasted. From the simulation it is shown that the load side management can help to utilize the produced energy efficiently. At the morning and evening time, when the net amount of solar PV generated energy is less than the traditional fixed load system, the $100 \%$ solar PV generated energy will be wasted, but the energy wastage is reduced to $2.16 \%$ in the morning and $0.81 \%$ in the evening with the proposed system for the given sample time as the automation unit is performing the load side management automatically. During this Covid-19 Pandemic it is very important to go for automation with high efficiency in load management. In the mid-day, when the net amount of solar PV generated energy is more than the traditional fixed load system, the total utilized energy will be equal to the value of the fixed load set. As a result, all the excess solar PV generated energy will be wasted. For example, for a given sample time of mid-day, when the energy utilization by the traditional fixed load system without energy trafficking is $64.33 \%$, the utilization is increased up to $99.92 \%$ with the proposed system where the energy trafficking is automated by an automation unit to perform the load side management. All the given data which 
have been presented in this paper for the considered test case scenario shows that the solar PV generated energy utilization can be maximized or the energy wastage can be minimized by the proposed system.

In the traditional fixed load system, to utilize the excess solar PV generated energy which is not utilized by the connected load instantly, can be used later with the help of a DC power storage facility. In that case, the maximum utilization of solar PV generated energy can be utilized with the help of a considerably large size of battery bank which involves a significant amount of cost, area and maintenance issues. Moreover, though a very large size of battery bank can increase the solar PV generated energy utilization up to $100 \%$, the $100 \%$ utilization of the installed battery bank cannot be possible throw out the year due to weather dependency. As a result, an economic design cannot be possible for the integrated renewable energy system in this way. To increase the cost efficiency, the size of the DC storage unit must be minimized to a point where the cost to utilization ratio will be at the lowest value. In that case, the $100 \%$ of solar PV generated energy utilization will not be possible.

Moreover, the DC power storage facility installation has been excluded from the proposed system as almost $100 \%$ solar PV energy utilization can be possible with the help of an automation system including the added advantages of an automation system like SCADA graphical user interfaces, data archiving, complying with all the guidelines of international regulatory authorities for pharmaceutical industries. As a result, the installation cost, area requirement, and maintenance issues will be no longer required for the DC power storage facility in the proposed system. To maintain the continuous power to the critical pharmaceutical machineries at the time of load shifting or energy trafficking, integrating the solar PV generated DC power with the existing online UPS system battery bank will ensure the reliability. Considering all the above stated cases, it shows that the proposed system will be more beneficial than the traditional integrated renewable power system for pharmaceuticals industry applications.

\section{ACKNOWLEDGMENT}

Special thanks to Dr. M. Tanseer Ali, Senior Assistant Professor, American International University-Bangladesh, for his valuable suggestions and cooperation.

\section{REFERENCES}

[1] Chin, Jacky; Lin Shu-Chiang; Persada, Satria Fadil; Mufidah, Ilma; Jaqin, Choesnul. Structural Behavior Analysis of Building Environment Automation System in Pharmaceutical Industries. Indian Journal of Public Health Research \& Development. Sep2019, Vol. 10 Issue 9, p687692. 6p.

[2] Reham M. Haleem, Maissa Y. Salem, Faten A. Fatahallah, Laila E. Abdelfattah. Quality in the pharmaceutical industry - A literature review. Saudi Pharmaceutical Journal (2015) $23,463-469$.

[3] R. S. Maya. (1989) Process automation in the pharmaceutical industry - a case study of process automation at the caps holdings drug factory, Information Technology for Development, 4:2, 253-258.

[4] Prof. Sirkka-Liisa, Jämsä-Jounela. Future Trends in Process Automation. IFAC Proceedings Volumes. Volume 40, Issue 1, 2007, Pages 1-10.
[5] V. Rajeswari, L. Padma Suresh and Y. Rajeshwari, "Water storage and distribution system for pharmaceuticals using PLC and SCADA," 2013 International Conference on Circuits, Power and Computing Technologies (ICCPCT), Nagercoil, India, 2013, pp. 79-86.

[6] Ilija Tabašević, Dragan D. Milanović, Vesna Spasojevic Brkić, Mirjana Misita. Temperature Mapping in Pharmaceutical Warehouse - Framework for Pharmacy 4.0. $\mathrm{X}$ International Conference Industrial Engineering and Environmental Protection 2020 (IIZS 2020), October 08-09, 2020, Zrenjanin, Serbia.

[7] H. Guo, C.L. Li, Y.K. Song, Q.W. Chu, Z.M. You, T. Tan, Y. He. The Design of an Automated High-Pressure Rinsing System for SRF Cavity and the Outlook for Future Automated Cleanroom on Strings Assembly. 19th Int. Conf. on RF Superconductivity, SRF 2019, Dresden, Germany.

[8] M. Allison, C.Eng., M.I.Mech.E., M.Inst.M.C. Building Management Systems in the Pharmaceutical Industry. Measurement and Control, Volume 29, September 1996.

[9] Anil K. Shukla, Ashutosh Katole, Nilesh Jain, C. Karthikeyan, Farhad Mehta and Piyush Trivedi. A Risk Assessment Approach: Qualification of a HVAC System in Aseptic Processing Area Using Building Management System. Quality Assurance Journal, 2011; 14, 40-49.

[10] L. Calderazzi; A. Pasini; F. Pedranzini. A pharmaceutical cleanroom HVAC system: energy audit and energy saving options. 46th AICARR International Conference, 2008, Milan, Italy; 04.1 Contribution in conference proceedings, pp. 699-715.

[11] Marwa M. Ibrahim, M. A. Badr, and Amal El Berry. Feasibility and Performance Analysis of Grid-Tied Solar Photovoltaic Systems Using PVsyst Simulation Package of Pharmaceutical Factory Case Study in Egypt. International Journal of Energy, Environment, and Economics, 2020, Volume 26, Number 4.

[12] Nicholas Mukisa, Ramon Zamora, and Tek Tjing Lie. Feasibility assessment of grid-tied rooftop solar photovoltaic systems for industrial sector application in Uganda. Sustainable Energy Technologies and Assessments, Volume 32, April 2019, Pages 83-91.

[13] K. Sangeetha, T. Sudhakar Babu, N. Sudhakar, and N. Rajasekar. Modeling, analysis and design of efficient maximum power extraction method for solar PV system. Sustainable Energy Technologies and Assessments, Volume 15, June 2016, Pages 60-70.

[14] B. Pakkiraiah and G. Durga Sukumar. Research Survey on Various MPPT Performance Issues to Improve the Solar PV System Efficiency. Journal of Solar Energy, Volume 2016, Article ID 8012432, pages 20.

[15] Bin-Juine Huang, Yin-Chen Huang, Guan-Yu Chen, PoChien Hsu, and Kang Li. Improving Solar PV System Efficiency Using One-Axis 3-Position Sun Tracking. Energy Procedia, Volume 33, 2013, Pages 280-287.

[16] Anshul Awasthia, Akash Kumar Shuklaa, Murali Manohar S.R., Chandrakant Dondariyaa, K.N. Shuklaa, Deepak Porwalab, and Geetam Richhariyac. Review on sun tracking technology in solar PV system. Energy Reports, Volume 6, November 2020, Pages 392-405.

[17] Arun Kumar Behuraa, Ashwini Kumarb, Dipen Kumar Rajakc, Catalin I. Pruncude, and Luciano Lambertif. Towards better performances for a novel rooftop solar PV system. Solar Energy, Volume 216, 1 March 2021, Pages 518-529.

[18] Hu Guozhen; Cai tao; Chen Changsong; Duan Shanxu. Solutions for SCADA system communication reliability in photovoltaic power plants. 2009 IEEE 6th International Power Electronics and Motion Control Conference, Wuhan, China, 2009, pp. 2482-2485.

[19] Abinet Tesfaye Eseyeab, Jianhua Zhanga, and Dehua Zhengb. Short-term photovoltaic solar power forecasting using a hybrid Wavelet-PSO-SVM model based on SCADA and Meteorological information. Renewable Energy, Volume 118, April 2018, Pages 357-367. 
[20] K. Sayed and H.A. Gabbar. Chapter 18 - SCADA and smart energy grid control automation. Smart Energy Grid Engineering, 2017, Pages 481-514.

[21] Rajeev Kumar, M. L. Dewal and Kalpana Saini, "Utility of SCADA in power generation and distribution system," 2010 3rd International Conference on Computer Science and Information Technology, Chengdu, China, 2010, pp. 648652.

[22] Lawrence Oriaghe Aghenta and Mohammad Tariq Iqbal. Low-Cost, Open Source IoT-Based SCADA System Design Using Thinger.IO and ESP32 Thing. MDPI Electronics 2019, Volume 8, Issue 8, pp. 822.

[23] L. O. Aghenta and M. T. Iqbal, "Development of an IoT Based Open Source SCADA System for PV System Monitoring," 2019 IEEE Canadian Conference of Electrical and Computer Engineering (CCECE), Edmonton, AB, Canada, 2019, pp. 1-4.

[24] Petru-Claudiu Pasc and Cristian-Dragos Dumitru. SCADA System for Solar MPPT Controller Monitoring. Procedia Technology, Volume 22, 2016, Pages 803-807.

[25] Part 11, Electronic Records; Electronic Signatures - Scope and Application. Available online: https://www.fda.gov/regulatory-information/search-fdaguidance-documents/part-11-electronic-records-electronicsignatures-scope-and-application

[26] EU GMP Annex 11: Computerized Systems. Available online: https://www.gmp-compliance.org/guidelines/gmpguideline/eu-gmp-annex-11-computerised-systems

[27] GAMP 5 Guide: Compliant GxP Computerized Systems. Available online: https://ispe.org/publications/guidancedocuments/gamp-5

[28] Historical Data: Glossary of terms. Available online: https://articles.solcast.com.au/en/articles/2790853historical-data-glossary-of-terms

[29] M. Munoz, M. Alonso-García, N. Vela, and F. Chenlo. Early degradation of silicon pv modules and guaranty conditions. Solar energy 2011, 85(9), 2264-2274.

[30] S. Forman. Performance of experimental terrestrial photovoltaic modules. IEEE Transactions on Reliability 1982, 31(3), 235-245.

[31] A. Houssein, N. Heraud, I. Souleiman, and G. Pellet. Monitoring and fault diagnosis of photovoltaic panels. IEEE International Energy Conference and Exhibition (EnergyCon) 2010, pp. 389-394.

[32] Mixed-Integer Linear Programming (MILP): Model Formulation. Available online: http://macc.mcmaster.ca/maccfiles/chachuatnotes/07-MILPI_handout.pdf

[33] Math. Graphics. Programming. Available online: https://www.mathworks.com/products/matlab.html

[34] Solcast's API Toolkit. Available online: https://solcast.com/solar-data-api/api-toolkit/

[35] About HOMER Energy LLC. Available online: https://www.homerenergy.com/company/index.html

[36] Improving Energy Efficiency in Pharmaceutical Manufacturing Operations; By Christina Galitsky, Shengchieh Chang, Ernst Worrell and Eric Masanet; Berkeley National Laboratory, Environmental Energy Technologies Division; Available Online: https://www.pharmamanufacturing.com/articles/2006/045/

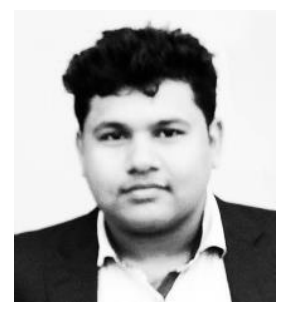

A.B.M. Khalid Hassan received the B.Sc. degree in Electrical and Electronic Engineering (EEE) from American International University-Bangladesh (AIUB) in 2016. He is currently pursuing the M.Sc. degree in Electrical and Electronic Engineering (EEE) at American International UniversityBangladesh (AIUB). From 2015, he is practicing on automation engineering field and working for different companies as a consultant and/or individual contractor. He is the owner of an automation engineering business and working for both local and international companies. He is a certified automation engineer accredited by Honeywell. Moreover, he is a certified project management professional (PMP) accredited by Qualifi as well. He is the author of 3 articles and his research interests include automation engineering.

Mr. Hassan was a recipient of the Outstanding Project \& Thesis Award from 16th Convocation of American International University-Bangladesh (AIUB) for Excellence in 2016. He is the Associate Member of Institution of Engineers, Bangladesh (IEB) and the Young Professionals of Institute of Electrical and Electronics Engineers (IEEE). Moreover, he is the Academic Coordinator of Society for the Popularization of Science, Bangladesh (SPSB) and Bangladesh Junior Science Olympiad (BDJSO).

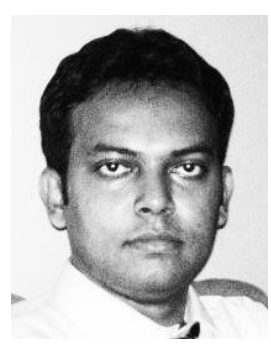

Kazi Firoz Ahmed is a PhD scholar at Islamic University of Technology (IUT). $\mathrm{He}$ is doing his $\mathrm{PhD}$ in the field of Power System Optimization. Currently, he is a Senior Assistant Professor of EEE Department, Faculty of Engineering, American International UniversityBangladesh (AIUB). He has been teaching and doing research in this University since 2010. He is the author of 12 published articles in journals and conference proceedings. He has worked as an editor of a published book. His research interest includes Renewable Energy, Power System, Machines and Drives.

Mr. Ahmed was a recipient of the OIC Scholarship from Islamic University of Technology (IUT) for Excellence in 2005. $\mathrm{He}$ is the Associate Member of Institution of Engineers, Bangladesh (IEB). 